\title{
AS ESTRATÉGIAS DOS ENFERMEIROS PARA O CUIDADO EM SAÚDE MENTAL NO PROGRAMA SAÚDE DA FAMÍLIA ${ }^{1}$
}

\author{
Aline Lage Amarante², Alessandra dos Santos Lepre³, João Leonardo Dias Gomes", Audrey Vidal Pereira ${ }^{5}$, \\ Virgínia Faria Damásio Dutra ${ }^{6}$
}

\footnotetext{
${ }^{1}$ A pesquisa faz parte do Trabalho de Conclusão de Curso, apresentando à Coordenação de Enfermagem do Centro Universitário Plínio Leite-Niterói (UNIPLI).

${ }^{2}$ Enfermeira. Rio de Janeiro, Brasil. E-mail: alinerjgm@gmail.com

${ }^{3}$ Enfermeira. Rio de Janeiro, Brasil. E-mail: ale.lepre@hotmail.com

${ }^{4}$ Enfermeiro. Rio de Janeiro, Brasil. E-mail: jlduvira@ig.com.br

${ }^{5}$ Mestre em Ciências. Professor Assistente da Escola de Enfermagem Aurora Afonso Costa da Universidade Federal Fluminense. Rio de Janeiro, Brasil. E-mail: auviprof@yahoo.com.br

${ }^{6}$ Doutoranda pela Escola Nacional de Saúde Pública da Fundação Osvaldo Cruz. Professora do UNIPLI. Rio de Janeiro, Brasil. E-mail: virginia.damasio@gmail.com
}

\begin{abstract}
RESUMO: A Reforma Psiquiátrica vem desfragmentando de modo processual a concepção de loucura na sociedade de forma a construir uma noção de cuidados às pessoas com sofrimento psíquico. Atualmente o direito a saúde é garantido via políticas públicas, inclusive pela Estratégia Saúde da Família. A intenção deste estudo é descrever as estratégias utilizadas pelos "enfermeiros da família" no cuidado com pacientes em sofrimento psíquico. Pesquisa descritiva com abordagem qualitativa, cujos dados foram obtidos através de entrevistas abertas e submetidos à análise de conteúdo. Identificamos que existe desconhecimento por parte dos enfermeiros sobre o termo sofrimento psíquico. Tem dificuldade de identificar a atenção à saúde dos portadores de sofrimento psíquico como parte da operacionalização das ações no cotidiano da Estratégia Saúde da Família. Mesmo não sendo planejadas de modo específico, existem estratégias indiretas de cuidado às pessoas em sofrimento.
\end{abstract}

DESCRITORES: Saúde mental. Saúde da família. Enfermagem em saúde comunitária.

\section{NURSING MENTAL HEALTH CARE STRATEGIES IN BRAZILIAN FAMILY HEALTH PROGRAM}

\begin{abstract}
Psychiatric reform has been procedurally defragmenting the process and conception of madness in society in order to build a notion of care for people with psychological distress. Currently the right to health in Brazil is guaranteed via public policies, including the Family Health Strategy The intent of this study was to discuss the strategies used by "nurses of the family" to care for people in psychological distress. This field research used a descriptive and qualitative approach to the data obtained through open interviews and then subjected to thematic content analysis. This study identifies a lack of knowledge among nurses interviewed concerning the term mental suffering. It is also difficult to identify care and concerns for health care patients with psychological distress as part of the operationalization of Family Health Strategy daily actions. Even not specifically planned, there are indirect care strategies for the people who are suffering.
\end{abstract}

DESCRIPTORS: Mental health. Family health. Health nursing community.

\section{ESTRATEGIAS DE LOS ENFERMEROS PARA EL CUIDADO EN SALUD MENTAL EN EL PROGRAMA DE SALUD DE LA FAMILIA}

\begin{abstract}
RESUMEN: La Reforma Psiquiátrica ha desfragmentado de manera procesal la concepción de la locura en la sociedad, a fin de construir un concepto de cuidado para las personas con trastornos psicológicos. Actualmente, el derecho a la salud se garantiza a través de políticas públicas, incluida la Estrategia de Salud de la Familia. El estudio tiene como objetivo describir las estrategias utilizadas por los "enfermeros de la família" en el cuidado a las personas con trastorno psicológico. Se trata de una investigación descriptiva con enfoque cualitativo, cuyos datos, obtenidos por medio de entrevistas abiertas, se analizaron por el método del análisis de contenido. Se identificó que existe desconocimiento por parte de los enfermeros entrevistados acerca del término sufrimiento mental. También existen dificultades para identificar el cuidado de los pacientes con trastornos psicológicos, como parte de la puesta en marcha de las acciones cotidianas de la Estrategia de Salud de la Familia. Aunque no han sido planeadas de modo específico, existen estrategias indirectas del cuidado a las personas que sufren.
\end{abstract}

DESCRIPTORES: Salud mental. Salud de la família. Salud enfermería comunidad. 


\section{INTRODUÇÃO}

Este estudo tem como objeto as estratégias utilizadas pelo enfermeiros para o cuidado das pessoas em sofrimento psíquico no âmbito da Estratégia Saúde da Família (ESF). A partir da década de setenta, a Reforma Psiquiátrica buscou transformar as relações entre a sociedade e a loucura, bem como o pré-conceito com os portadores de transtornos mentais. A Reforma Psiquiátrica compreende um conjunto de transformações permanentes que ocorrem nos campos teóricos, assistenciais, jurídicos e socioculturais, marcada por tensões, conflitos e desafios ao propor a retirada do paciente com transtorno mental dos hospitais psiquiátricos e proporcionar cuidados necessários na comunidade. Aos poucos, desfragmentou-se a idéia de asilo e ocorreu a integração de novos serviços de saúde, dentre eles a ESF. Assim o portador de transtorno mental severo e persistente, ou de sofrimento psíquico leve, adquiriu legalmente o status de cidadão, com direito às mesmas possibilidades que qualquer outra pessoa ao se falar de atenção à saúde. ${ }^{1}$

A constituição e implementação do Sistema Único de Saúde (SUS), na década de noventa, procura defender os direitos, os deveres e o compromisso com a saúde, fundamentados nos princípios: integralidade, igualdade, equidade e universalidade. Com tais princípios, as equipes de saúde da família buscam um cuidado integral, a promoção da saúde, e resultados importantes para a saúde coletiva, seja no aspecto físico, psíquico ou social. ${ }^{1}$

Em todo território nacional, a ESF é operacionalizada com equipes de saúde compostas minimamente por um médico, um enfermeiro, um auxiliar de enfermagem e seis ou mais agentes comunitários de saúde, sendo incluídas a partir de 2000, as equipes de saúde bucal. ${ }^{2}$ Profissionais como psicólogos, assistentes sociais, nutricionistas, dentre outros, podem ou não fazer parte da equipe, como podem fazer parte de uma equipe de apoio. ${ }^{3}$

De acordo com o Ministério da Saúde, o enfermeiro na ESF tem enquanto atribuições: planejar, gerenciar, coordenar, executar e avaliar, priorizando a assistência integral na Unidade de Saúde de Família (USF), levando em conta as reais necessidades da população. Esse crescimento vem ampliando o acesso da população, inclusive de grupos sociais até então excluídos, aos serviços de atenção básica de saúde e organizando a demanda aos demais níveis de atenção á saúde. ${ }^{4}$
Assim, as equipes de saúde da família devem utilizar variadas estratégias com o objetivo de resolver os problemas de saúde pública, investindo cada vez mais na formação de vínculos com a comunidade. Devem acolher e se responsabilizar da melhor forma possível, dentro de cada realidade, pelas diversas formas de sofrimentos que acometem a população de modo geral. Com isso, verifica-se a necessidade de integração das ações da Saúde Mental e da Atenção Básica, visto que toda e qualquer doença possui seu sofrimento subjetivo, então todo problema de saúde também é de saúde mental e toda saúde mental é sempre produção da saúde. ${ }^{1}$

Considera-se sofrimento psíquico, um conjunto de mal-estares e dificuldades de conviver com a multiplicidade contraditória de significados da vida, relacionados às dificuldades de operar planos, definir o sentido da vida. Ou ainda, relacionada ao sentimento de impotência e de vazio. ${ }^{5}$

Para que a sociedade possa lidar com as formas diferentes de sofrimento psíquico, ou com sofrimentos de qualquer natureza, é necessário que o sistema de saúde o enxergue sem preconceitos, considerando simplesmente as condições como ser humano, abandonando a concepção de cura e adotando a concepção de cuidado, fundamentada na humanização e na subjetividade dos seres (Psíquico) imersos no contexto social, como propunha a Reforma Psiquiátrica. ${ }^{6}$ É assim que se busca a atenção integral necessária a qualquer tipo de sofrimento. Dessa forma, para almejar a atenção integral o enfermeiro da ESF deve buscar a multidisciplinaridade, a interdisciplinaridade, os recursos materiais e os recursos da comunidade. ${ }^{1}$

Em uma pesquisa realizada na ESF de Campina Grande-PB, foi possível identificar que os enfermeiros demonstram a importância da atenção que se deve oferecer ao usuário do SUS, escutando suas necessidades e tendo um olhar atento às diferentes formas de sofrimento, mesmo sem possuir um serviço formalmente estruturado e identificado como acolhimento, realizado por demais profissionais de saúde como assistentes sociais, psicólogos e psiquiatras. ${ }^{7}$ Aponta ainda que o profissional da saúde deve atuar sempre em conjunto com a população, tentando interagir com a família, estando presente para observar, acolher e cuidar promovendo a autonomia em cada indivíduo. ${ }^{7}$ Assim, compartilhar a compreensão de estratégias utilizadas atualmente pelos enfermeiros para operacionalizar ações que incluam atenção ao sofrimento psíquico no âmbito da saúde da 
família, pode contribuir de modo a implementar reorientações do modelo de assistência à saúde em todo território nacional.

Com base nestas reflexões surge a iniciativa de compreender como tem sido a prática dos enfermeiros que atuam na ESF para o cuidado das pessoas com sofrimento psíquico. Para tal, tem-se como objetivo descrever as estratégias utilizadas pelos "enfermeiros da família" no cuidado com pacientes em sofrimento psíquico.

O estudo justifica-se pela reorientação do modelo assistencial proposta pela Lei Federal 10.216. ${ }^{8}$ E ainda, pelo imperativo da Declaração de Caracas $^{9}$, que determina que atenção em saúde mental deve acorrer na comunidade onde se vive, de forma: descentralizada, participativa, integral, contínua e preventiva.

\section{MÉTODO}

Este estudo é de caráter descritivo, com abordagem qualitativa. ${ }^{10}$ A pesquisa descritiva expõe as características de uma determinada população ou fenômeno não tem compromisso de explicar os fenômenos que descreve, embora sirva de base para explicação. A pesquisa qualitativa facilita descrever a complexidade de um determinado problema analisar a interação de certas variáveis. Apresenta contribuições no processo de mudança, na criação e formação de opiniões de determinado grupo, permitido em maior grau de profundidade, a interpretação das particularidades dos comportamentos ou atitudes dos indivíduos. ${ }^{10}$

A pesquisa de campo foi escolhida com a intenção de buscar elementos para poder explicar um fenômeno que ocorre ou ocorreu num determinado local. ${ }^{11} \mathrm{~A}$ técnica de coleta de dados utilizada foi a entrevista aberta. O cenário da pesquisa foram 20 ESFs de um município localizado na região metropolitana II do Estado do Rio de Janeiro, da subregião cinco, do município de São Gonçalo-RJ. Os sujeitos da pesquisa foram 20 enfermeiros das respectivas ESFs, que aceitaram participar voluntariamente da pesquisa. As entrevistas foram realizadas no local e no horário de trabalho dos enfermeiros, gravadas em fitas $\mathrm{K} 7$, transcritas e destruídas imediatamente, preservando a identidade dos entrevistados os quais foram identificados no texto através do número das entrevistas $\left(\mathrm{E} \mathrm{n}^{\circ}\right)$. Para garantir a legitimidade e resguardar os sujeitos da pesquisa, foram respeitados os quatro referenciais básicos da bioética: autonomia, não maleficência, beneficência e justiça. A coleta de dados foi reali- zada com a pergunta: Qual a estratégia adotada pelo enfermeiro da ESF ao "paciente" portador de sofrimento psíquico? Por ser uma entrevista aberta e ter um tema específico, coube ao entrevistador sempre retornar ao foco da mesma. ${ }^{10}$

O projeto foi submetido à aprovação do Comitê de Etica em Pesquisa da Escola de Enfermagem Anna Nery, de acordo com a resolução 196/96, protocolo de $n^{0} 105 / 08$. Os enfermeiros foram convidados a participar da pesquisa e, na ocasião, lhes foi apresentado o projeto; ao aceitar, foram incluídos como sujeitos do estudo e assinaram um termo de consentimento livre e esclarecido, garantindo o anonimato e permitindo se ausentar a qualquer momento da pesquisa sem nenhum prejuízo.

O dados foram tratados pelo método de análise de conteúdo, ${ }^{11}$ modalidade temática definida como procedimento sistemático de objetivos, de descrição do conteúdo das mensagens, assim como indicadores que permitam a inferência de conhecimentos relativos às condições de produção/recepção destas mensagens. A análise se construiu nas etapas: leitura exaustiva das entrevistas transcritas, definição das Unidades de Registros (UR), marcação das Unidades de Significação (US), estabelecimento de categorias temáticas e descrição das categorias e análise fundamentada no referencial teórico.

Na análise das entrevistas relacionadas às estratégias para o cuidado em saúde mental na ESF, realizou-se a separação dos temas e o agrupamento dos dados em categorias temáticas. Estabeleceu-se a compreensão dos dados coletados obtidos das questões da pesquisa. ${ }^{11} \mathrm{~A}$ análise dos dados resultou em três categorias temáticas: 1) O sofrimento psíquico na ESF; 2) Dificuldades de incluir a atenção à saúde do portador de sofrimento psíquico na Saúde da Família e 3) Estratégias de atenção à saúde mental na Saúde da Família.

\section{RESULTADO E DISCUSSÃO DOS DADOS}

\section{O sofrimento psíquico na ESF}

Ao fazer o questionamento: Existe portador de sofrimento psíquico ou transtorno mental com ou sem diagnóstico em sua área de atuação? Observou-se o aparecimento de sete UR, sinalizando que "não existe portador de transtorno mental" sendo atendido na ESF. Em 20 entrevistas, seis enfermeiras, inicialmente, afirmaram não existir 
portador de transtorno mental em seu território de abrangência, demonstrando desconhecimento por parte das mesmas, à respeito do uso do termo sofrimento psíquico, como nas falas: [...] olha, na minha área, que a gente acompanha, não tem portador de sofrimento mental não, a gente tem muito alcoólatra (E3). Na minha área diretamente eu não tenho. Nós temos alguns alcoólatras (E9).

Foi possível identificar UR, tais como: viciados, bêbados, alcoólatras, síndrome do pânico, pico mental, descontrole mental, distúrbio, psicótico, mania, abalo emocional, estresse emocional, não quer mais viver, depressão e depressão pós-parto, que confirmam desconhecimento teórico sobre o conceito sofrimento psíquico, mas o reconhecimento do transtorno mental severo e persistente. Vide a fala: é uma pessoa psicótica, que parou de tomar seus remédios (E5).

Mesmo sendo minoria, o quantitativo de enfermeiros que demonstrou dificuldade/distanciamento do termo sofrimento psíquico compreendendo-o como doença, e não como sintoma difuso, ou sofrimento relativo à vida. Isso corrobora a carga de preconceito em torno do "doente mental" e do "manicômio".

As expressões: "não entendimento do papel do enfermeiro na ESF" (21 UR) e o "distanciamento do cuidado" (18 UR) possibilitam, por sua vez, interpretar que os enfermeiros também apresentam dificuldade em entender a própria prática no âmbito da Saúde da Família, sob a égide dos princípios doSUS. Os entrevistados afirmam: eu sei que o enfermeiro tem mania de ser psicólogo, assistente social, né? Nutricionista [...]. Aí tem " $n$ " coisas que você pode fazer [...]. Eu não vejo como uma continuidade de um trabalho que você possa começar dentro do PSF (E5); eu acredito que aqui no bairro deva existir, mas eles não nos procuram, pelo menos enquanto estou aqui (E13); eles que nos procurem (E13); eu não tenho muito a acrescentar não, até porque é uma área que eu não tenho muita afeição por ela, que é a psiquiatria (E14); existe preconceito em não valorizar o que o paciente está sentindo (E16).

Os enfermeiros apontam dificuldades de cuidar das pessoas, integralmente. Referem as especialidades com justificativas para atender às questões subjetivas e esperam que as famílias venham até o posto, contrariando a filosofia da ESF e os princípios do SUS. Os enfermeiros enfatizam suas responsabilidades com as doenças, com aspecto o biológico, ou procedimentos com o corpo.

Em um estudo sobre a constituição de competência na formação do enfermeiro para atuar em saúde mental, os resultados apontam um saber prescritivo, que revelou a pouca resolução dessa competência, diante de situações de trabalho. ${ }^{12}$ Concluiu que, ao descrever normas e rotinas específicas de cada profissional, não estão constituindo saberes, não mobilizam habilidades e conhecimentos para o enfrentamento de situações reais na atenção em saúde mental. ${ }^{12}$

Entretanto, os dados trazem, ainda, o preconceito em relação à psiquiatria e às dificuldades de alguns enfermeiros em acolher a pessoa em sofrimento psíquico, corroborando a ideia de que os profissionais da saúde acabam focalizando suas ações no cuidado ao corpo e detrimento às questões subjetivas. ${ }^{13}$ As falas dos sujeitos do estudo referente ao fazer da enfermagem estão centradas nos aspectos biológicos, então, a princípio os enfermeiros não identificam como responsabilidade profissional a atenção à saúde mental, ou seja, não consideram na sua prática o conceito ampliado de saúde, como propõe a ESF. ${ }^{2}$

Fundamentado nas ideias trazidas: Triagem (12 UR), Encaminhamento (29 UR) e Exclusão da Saúde Mental na ESF (19 UR), é possível reafirmar que os enfermeiros demonstram dificuldades em identificar sofrimento psíquico no âmbito da ESF. Ao se depararem com um portador de sofrimento, imediatamente encaminham-no aos profissionais especialistas da saúde mental. Não demonstram disponibilidade para o acolhimento, a escuta, a formação de vínculos e o apoio social destas pessoas.

Os enfermeiros pontuam que a equipe não está apta a atender esse paciente, nem mesmo tem suporte para ser dado aos "pacientes" na unidade de saúde da família. Então, encaminham-nos ao psiquiatra e/ou ao psicólogo em serviços especializados: eu não posso ter esse paciente comigo aqui, porque a minha área é PSF e ela não comporta esse tipo de problema, pessoas com problemas mentais, distúrbios neurológicos, psíquico, tudo isso vai para área que seja de tendência para ele. Eu não posso dar um diagnóstico, eu não posso está relatando nada, porque eu só entendo da parte clínica (E2); a gente dá os endereços para as famílias e para as pessoas, quando quer (E3); aqui a gente só acompanha para encaminhar para o psicólogo. Na realidade, eu sou enfermeiro e não psicólogo (E6); aqui a enfermagem só atua nas consultas, nenhum outro acompanhamento só do CAPS (E19).

Assim, os enfermeiros entrevistados ressaltam a impossibilidade de atender a pessoa em sofrimento psíquico na ESF, desacreditam da autonomia desta pessoa, não reconhecem a lógica 
do território e encaminham aquelas pessoas que demandam atendimento psíquico aos serviços especializados.

Todavia, segundo o Código de Ética de Enfermagem, o enfermeiro deve ter como preocupação primordial a assistência no cuidado ao ser humano como um todo e sua coletividade. A enfermagem deve estar pronta a promover a saúde, respeitando a vida sem discriminação de qualquer natureza, ${ }^{14} \mathrm{em}$ qualquer local que tenha atuação profissional do enfermeiro e equipe. $\mathrm{O}$ Código de Ética assegura uma atenção integral a todo ser humano, corroborando a Lei Federal 10.216, de 06 de abril de 2001, ${ }^{8}$ que protege todo portador de transtorno mental, sem discriminação de qualquer gênero ou espécie, suprindo todas as suas necessidades, respeitando-o e acolhendo-o com igualdade, e a Lei 8.080 de 19 de setembro de 1990, que afirma que saúde é direito fundamental do ser humano, implicando na prevenção da autonomia e na defesa da saúde, sua integralidade física e moral. ${ }^{7}$

Deste modo, o SUS traz a igualdade na assistência sem preconceitos ou privilégios de qualquer espécie, buscando apoio multidisciplinar através da articulação e participação da população. ${ }^{15}$ Os princípios e diretrizes do SUS, tem origem na busca por qualidade de vida das pessoas e no desenvolvimento de ambiente saudáveis. A atenção à saúde deve ser integral, universal, promovendo a resolutividade, intersetorialidade, equidade e humanização no atendimento para garantir o vínculo com a população que deve estar presente nas decisões e melhorias na assistência. ${ }^{1}$

Sob essa perspectiva, o portador de sofrimento psíquico deve ter garantida a assistência a sua saúde, de modo transversal, em todos os níveis de atenção à saúde da população, não somente em serviços especializados. $\mathrm{O}$ enfermeiro deve prestar o cuidado integral, contínuo e participar dos programas realizados na área adstrita, promovendo a saúde individual ou em grupos, detectando, o mais rápido possível, as necessidades da assistência de enfermagem, buscando apoio de qualidade no território e não se limitando aos recursos provenientes da ESF. ${ }^{1,16}$

Assim sendo, a dificuldade e/ ou o desconhecimento por parte dos profissionais enfermeiros em lidar com portadores de sofrimento psíquico (mental leve ou severo e persistente) no processo de trabalho da saúde da família, faz com que haja repercussão direta no distanciamento de uma prática pautada nos princípios do SUS.
Dificuldades de identificar e incluir a atenção à saúde do portador de sofrimento psíquico na Saúde da Família

De acordo com o SUS, a ESF é composta por profissionais capazes de assistir aos problemas de saúde mais comuns, não se limitando à triagem e ao encaminhamento aos serviços especializados. $\mathrm{O}$ sofrimento psíquico faz parte do contexto de vida, assim, torna-se possível reafirmar que a Saúde da Família é capaz de acompanhar a saúde dessas pessoas atendendo aos diversificados aspectos que envolvem a vida. ${ }^{2}$

No entanto, essa prática não é comum no dia a dia dos profissionais de saúde da família. Deste modo, essa categoria temática torna visível as dificuldades apresentadas pelos enfermeiros entrevistados, em identificar e operacionalizar ações que atendam a saúde dos portadores de sofrimento psíquico como parte inclusiva do processo de trabalho da Saúde da Família. Assim sendo, os enfermeiros apontaram nas entrevistas que as limitações encontradas na ESF são os problemas dos pacientes: [...] a maioria tem dificuldades em relação à família, ao próprio tratamento, de locomoção (E14); porque ela mora no centro espírita e todos acham que é espiritual (E7); então eles ficam caídos pelas ruas bêbados (E3); [...] a minha área é super pobre, tem pessoas que moram na beira do valão e não têm nem o que comer (E8); acontece de tudo, a mãe e o pai brigando, o pai batendo na mãe, tem tudo isso (E15).

Também aparecem nas falas, as Dificuldades do Enfermeiro (19 UR) e da Estratégia de Saúde da Família (27 UR) para proporcionar um atendimento de qualidade ao portador de sofrimento. As entrevistas trazem unidades de significação como: falta de respeito dos pacientes, preconceito dos profissionais ao paciente com transtorno mental, falta de parceria com a comunidade e a família, falta de capacitação de qualidade aos profissionais, abandono dos pacientes ao tratamento, falta de medicação, difícil acesso ao paciente internado e seu diagnóstico, dificuldade financeira e dificuldade de diálogo com o paciente, exemplificado nas falas: [...] ainda existe um preconceito muito grande em relação a qualquer portador de deficiência a nível mental (E12); [...] muitas vezes eu não sei como me comportar em determinadas situações (E15).

Além destas dificuldades, ainda surge, mesmo que em minoria, registros correlacionados à Pequena Parceria Especializada na ESF (6 UR), mostrando que três dos enfermeiros visitados sentem necessidade do profissional psicólogo na equipe, ressaltando ainda as poucas referências em 
saúde mental na rede. Afirmam: [...] teria que ter um acompanhamento de um psicólogo, psiquiatra, ali dando um apoio e a gente não tem isso (E5); [...] fica faltando um suporte melhor para aquela família (E12).

No que se refere às questões de baixa complexidade de atenção à saúde, acredita-se que a ESF seja capaz de efetivar suas metas com as ações desenvolvidas pela equipe mínima composta por profissionais generalistas (enfermeiro e médico). Assim, entende que os psicólogos e os psiquiatras não são necessários de modo direto como parte integrante desta equipe podendo prestar um atendimento qualificado à comunidade sem esses profissionais especialistas. ${ }^{1,16}$ Contudo, na Atenção Primária, o desafio de atender de modo integral a saúde dos indivíduos é complexo por se tratar de pessoas com sofrimentos diversos e por necessitar de vários serviços que vão além do setor saúde.

Entre os desafios a serem enfrentados pela ESF estão a formação de competências ${ }^{12}$ e habilidades com base nas relações partilhadas, como as tecnologias leves de acolhimento, vínculo e responsabilização, e assim, ampliar o acesso às ações da saúde oferecidas à população em busca da integralidade da assistência. É preciso envolver os trabalhadores para que usem seus arsenais tecnológicos na busca de serviços eficientes e satisfação das necessidades da população. ${ }^{17}$ Desse modo, é preciso investir na formação de profissionais, seja na graduação, na educação continuada ou permanente.

No entanto, o serviço deve responsabilizarse pela saúde mental de toda a área territorial de referência e isto pressupõe um papel ativo na sua promoção. No entanto, essa tarefa não pode ser restrita aos serviços de saúde mental. Estes, juntamente com os demais segmentos sociais que compõem a rede social, devem articular-se a fim de promover melhoria nas condições de saúde e de vida das pessoas. É preciso ocupar-se de tudo aquilo que se construiu em torno dos problemas. ${ }^{6}$

\section{Estratégias de atenção à saúde mental na Saúde da Família}

Mesmo não sendo planejadas de modo específico, nem tendo sido identificadas amplamente como ações que atendam aos portadores de sofrimento psíquico, existem estratégias indiretas de cuidado às pessoas com sofrimento no âmbito da saúde da família. Essa categoria resultou das falas ao questionamento sobre as estratégias adotadas pelos enfermeiros para a atenção à saúde mental na ESF. Dos entrevistados verificou-se que alguns afirmam inicialmente não atender à saúde mental ou não existir portador de transtorno mental no território da Saúde da Família.

Mesmo utilizando o termo sofrimento psíquico, sem diagnóstico psiquiátrico, nos questionamentos aos enfermeiros, eles continuaram a afirmar não existir portador de sofrimento psíquico no território (sete entrevistas). Mas, no decorrer das entrevistas, os enfermeiros se mostravam confusos e afirmavam existir, em seu território, portadores de sofrimento psíquico (19 entrevistas).

As UR, tais como: abalo emocional, pico mental, alcoólatras, depressão, depressão pósparto, mania e maníaco, torna-se possível confirmar a existência de portadores de sofrimento nas relações com os enfermeiros. Esses dados demonstram que o termo sofrimento psíquico não tem significado para a prática do enfermeiro na ESF, no entanto, os mesmos o reconhecem como sofrimento. Os respectivos dados sugerem que o termo "psíquico" suscita intervenção psiquiátrica tradicional, por isso os enfermeiros de família não o identificam, a princípio, mas o reconhecem posteriormente, a partir da internação psiquiátrica. No modelo psiquiátrico, nascido no modelo biomédico, acreditava-se na ciência enquanto intervenção no processo patológico (hospitalização), enquanto que no modelo em que se instalou a atenção psicossocial, depara-se com o sujeito com suas vicissitudes e uma ampliação da noção de integralidade. ${ }^{6}$

Os entrevistados apontam como estratégias dos enfermeiros para atender à saúde mental (138 UR), no processo de trabalho da Saúde da Família, unidades de significação como: atendimento em grupo, acompanhamento, visita domiciliar, atendimento à família, escuta, parcerias com a comunidade, conversa, oferecer informações e auxiliar na medicação, como apresenta nas falas seguintes: de 15 em 15 dias, a gente faz um "Grupo de Terapia de Abalos Emocionais" (E1); a gente os inclui nas visitas domiciliares (E5); a gente conversa (E12); dando orientação à família (E10); eles só precisam que você escute um pouco dos problemas deles (E15); a gente avalia o paciente, a gente vê a parte clínica com a médica, a gente acompanha as situações (E18).

As estratégias assinaladas concordam com os objetivos de atenção à saúde de modo geral. $\mathrm{O}$ enfermeiro deve prestar um atendimento integral, englobando o indivíduo e sua família, suprindo suas necessidades primárias ao se tratar da saúde mental, em qualquer nível de atenção à saúde. Em 
cada lugar existe uma realidade diferente para cada família. A equipe, ao conhecer tal realidade, aproveita sua proximidade com a população e monta em conjunto suas estratégias de atenção e acolhimento a família. ${ }^{13}$ Dessa forma, parte importante do contexto de saúde e problemas vinculados ao uso abusivo de álcool, drogas e diversas outras formas de sofrimento psíquico.

Os enfermeiros buscam, dentro de sua realidade, estratégias que apóiam continuamente a família como um todo, adaptando-se à comunidade, buscando a melhor forma de abordagem, inserindo as estratégias em equipe, como as terapias em grupos, as visitas domiciliares e o simples ouvir aos pacientes. Das vinte entrevistas, apenas sete mostram com clareza que estão buscando meios em meio às dificuldades, estratégias para atender à demanda de sofrimento da comunidade.

Surgiram ainda, unidades de significação referentes às estratégias da equipe (11 UR) apontadas como sendo: medicação, visita domiciliar, acompanhamento da equipe e homeopatia. A ESF tem intenção de promover a saúde ao cidadão, estando vinculada a uma rede de serviços, a fim de garantir uma atenção integral e contínua às famílias. As estratégias da equipe de saúde devem ser construídas junto à comunidade, mostrando sua opinião e satisfação, num processo democrático. ${ }^{16}$

A atenção básica traz na sua filosofia ações articuladas, como a visita domiciliar, a potencialização de recursos comunitários, ações intersetoriais, oferta de atividades tais como esportes comunitários, grupos de mães, de mulheres, de idosos, oficinas de artes e de ofícios, grupos educativos, de apoio, lazer, entre outros, garantindo o atendimento integral ao paciente e a sua família. ${ }^{16}$

Desse modo, a ESF tem com meta principal a promoção da saúde. Um dos grandes desafios do cuidado da promoção da saúde é a de mudança nas condições de vida. A construção da qualidade e o desenvolvimento humano envolvem a solidariedade, interdisciplinaridade, articulação e comunicação entre os atores sociais, para que possam contribuir com a melhoria da qualidade de vida da população. ${ }^{18}$

Dentre as unidades de registros correlacionadas às estratégias de saúde mental, no cotidiano da saúde da família, observou-se um movimento referente à avaliação das mesmas. Estas avaliações das estratégias (58 UR), mencionadas pelos enfermeiros, foram divididas em positivas (39 UR) e negativas (19UR). Os enfermeiros avaliam as estratégias utilizadas como negativas a partir das se- guintes unidades de significação: abordagem sem efeito, falta de qualificação profissional e estrutura adequada, falta de grupos de apoio específico à comunidade, acompanhamento clínico, involuções dos casos, falta de retorno, PSF vira ambulatório e falta de gente para atuar num território extenso, como nas expressões: de todos os pacientes que eu tive aqui nesses sete meses, nenhum quis se tratar (E3); em São Gonçalo a gente tem uma certa deficiência de acompanhamento (E11); a gente não vê uma resposta muito positiva (E14); o PSF não está funcionando como deveria, ele está funcionando como ambulatório (E18); quanto ao tratamento mental, a gente não tem nenhuma atuação, nem nós nem o médico (E20).

A avaliação negativa mostra desafios para ESF. As equipes realizam inúmeras atividades determinadas pela gestão, estas atividades avaliam quantitativamente a produção das equipes na comunidade, para fornecer os incentivos necessários à manutenção das atividades cotidianas. ${ }^{16}$ Assim, acabam por valorizar ações programadas como atendimento de hipertensos e diabéticos, e não ressaltam a importância de ações transversais, como as de promoção à saúde mental na ESF, até mesmo porque não são quantificáveis.

Como avaliações positivas, apontam unidades de significação como: o bem-estar dos usuários da ESF, a retirada das medicações controladas, o aumento da demanda, o aprendizado e a satisfação da equipe, a aprovação da população e a ressocialização dos pacientes. Por exemplo: desses 25 [participantes do grupo], uns 15 já foram liberados de praticamente quase tudo, não tomam mais remédios controlados, já estão trabalhando e houve um apoio da unidade com toda a comunidade (E12).

Já a avaliação positiva demonstrada pelos enfermeiros ressalta que o trabalho e o esforço profissional na Saúde da Família são importantes para os trabalhadores, usuários e, consequentemente, para a sociedade. É interessante destacar, sob a perspectiva de questões positivas que, para alguns profissionais, existe Parceria Especializada em Saúde Mental (10 UR). Pode-se identificar parcerias entre alguns segmentos da rede comunitária e a ESF, tais como os grupos de Alcoólatras Anônimos (AA), o Pólo Sanitário de Saúde (unidade de referência ao nível secundário de atenção à saúde), o Centro de Referência e Assistência Social (CRAS) e o Centro de Atenção Psicossocial (CAPS).

A realização de parcerias é uma forma de corrresponsabilização, unindo o suporte técnico de equipes responsáveis pela promoção à saúde e desenvolvimento das ações básicas, aos esforços 
empreendidos de órgão governamentais e não governamentais de variados setores, atuando de forma integral, a partir de intervenções conjuntas junto às famílias e à comunidade. ${ }^{1,6,13} \mathrm{O}$ apoio matricial representa um arranjo organizacional entre a atenção básica e um CAPS, visando a ampliação e reorientar a demanda para a saúde mental. Fundamentado no princípio da responsabilização compartilhada, ele pretende produzir maior resolutividade à atenção em saúde. ${ }^{19}$

Esses novos arranjos devem ser transversais, no sentido de produzir e estimular padrões de relação que perpassem todos os trabalhadores e usuários, favorecendo a troca de informações e a ampliação do compromisso dos profissionais com a produção de saúde. O apoio matricial elimina a lógica do encaminhamento para outros serviços, mas construção de projetos terapêuticos que são executados por um amplo conjunto de trabalhadores.

Todos esses serviços contribuem para a qualidade de vida dos portadores de algum tipo de sofrimento psíquico diagnosticado. O CAPS tem a responsabilidade de prestar um atendimento especializado aos portadores de transtorno mental severo e persistente e ainda gerenciar a rede de Atenção à Saúde Mental no seu território, considerando que compartilha o mesmo território com a ESF, é um parceiro na promoção da saúde mental, incluindo nessa parceria o suporte e o treinamento de profissionais da atenção básica e promovendo a inserção social dos portadores de sofrimento psíquico. ${ }^{1}$

Os profissionais que trabalham em serviços orientados pela lógica do território (CAPS e ESF) são, portanto, agentes terapêuticos do território. Então, descobrir e ativar os recursos escondidos e estabelecer alianças, representa mais um grande desafio. ${ }^{20}$ Trabalhar no território significa resgatar todos os saberes e potencialidades dos recursos da comunidade, construindo coletivamente soluções, a multipliciadade de trocas entre as pessoas e os cuidados em saúde. ${ }^{1}$

Os sujeitos da pesquisa apontam dificuldades em estabelecer articulações com outros serviços de saúde, outros setores e com a comunidade. No entanto, se considerarmos o conceito ampliado de saúde, se faz necessário o desenvolvimento da comunidade como um todo, inclusive a formação dos profissionais da ESF. As estratégias apontadas pelos entrevistados, mostram passos para adotar a atual política de saúde no Brasil.

\section{CONSIDERAÇÕES FINAIS}

Os enfermeiros entrevistados não se mostram familiarizados com as expressões "sofrimento psíquico" ou "transtorno mental" na ESF, mas apontam variadas estratégias de atenção à saúde mental na mesma. Grande parte dos enfermeiros não as planeja de modo direto e/ou intencional, no entanto, existem aqueles que assumem o papel de escutar, acolher, visitar, articular e, por vezes, afirmam se responsabilizar pelo cuidado de pessoas com sofrimento dentro do território.

As limitações da ESF mostraram que se as dificuldades existentes na relação com portadores de sofrimento psíquico fossem diminuídas e a aproximação/ pactuação com várias parcerias fosse ampliada, ou melhor, articuladas, só restariam problemas de responsabilidade individual dos pacientes, sendo que a maior parte dos problemas identificados como dos pacientes é resultado das limitações das estratégias da Saúde da Família, inserida na rede de atenção à saúde no município.

$\mathrm{Na}$ avaliação das estratégias de atenção à saúde mental, foi observada a existência de enfermeiros que possuem atividades relevantes para a comunidade e apresentam avaliações positivas. Entretanto, as respectivas ações precisam ser mais valorizadas pelo profissional generalista, pois a maioria ainda identifica a necessidade de um especialista para lidar com o sofrimento psíquico. O enfermeiro de família deve buscar na multidisciplinaridade, na formação de parcerias intersetoriais e na participação social dos usuários, a ampliação do nível de saúde da comunidade.

Desta maneira, a Saúde da Família é uma estratégia que torna viável a efetivação de ações que envolvam acolhimento, cuidado e trocas sociais. Não somente a articulação com a rede dos serviços específicos de saúde mental e a parceria com outras instituições, associações, cooperativas e variados espaços da sociedade são importantes para efetivar cuidados aos portadores de sofrimento, mas também a assunção de responsabilidade no lócus do processo de trabalho dos profissionais generalistas da saúde da família passa ser peça fundamental para a constituição de respostas concretas que atendam, de modo integral, todas as pessoas em sofrimento psíquico.

\section{REFERÊNCIAS}

1. Ministério da Saúde (BR). Reforma psiquiátrica e política de saúde mental no Brasil: Conferência 
regional de reforma dos serviços de saúde mental: 15 anos depois de Caracas. Brasília (DF): MS; 2005.

2. Ministério da Saúde (BR). Secretaria de Atenção à Saúde. Departamento de Atenção Básica. Avaliação para melhoria da qualidade da estratégia saúde da família. Brasília (DF): MS; 2005.

3. Fontinele Junior K. Programa Saúde da Família: (PSF), $2^{\mathrm{a}}$ ed. Goiânia: AB; 2008.

4. Ministério da Saúde (BR). Secretaria de Atenção à Saúde. Departamento de Atenção Básica. Saúde da família no Brasil: uma análise de indicadores selecionados: 1998-2005/2006 . Brasília (DF): MS; 2008.

5. Schneider FJ, Tonini NS, Maraschin MS, Durman S, Dias TA e Tomazzoni MI. Indicadores do sofrimento psíquico na zona urbana do município de Cascavel-PR. Rev Acta Scientiarum. 2003 Jan-Jun; 1(25):27-33.

6. Amarante P. Saúde mental e atenção psicossocial. Rio de Janeiro (RJ): Fiocruz; 2007.

7. Silveira MFA, Felix LGF, Araújo DVA, Silva ICS. Acolhimento no programa saúde da família: um caminho para humanização da atenção à saúde. Cogitare. 2004 Jan-Jun; 9(1):71-8.

8. Brasil. Lei 10.216 de 06 de Abril de 2001. Dispõe sobre a proteção e os direitos das pessoas portadoras de transtornos mentais e redireciona o modelo assistencial em saúde mental. Diário Oficial da República Federativa do Brasil, 09 Abril 2001. Seção 1.

9. Ministério da Saúde (BR). Declaração de Caracas [Internet]. 1990 [acesso 2008 Ago 22]. Disponível em: http:// pfdc.pgr.mpf.gov.br/atuacao-e-conteudosde-apoio/legislacao/saude-mental/declaracao_ caracas

10. Minayo MCS, organizador. O desafio do conhecimento: pesquisa qualitativa em saúde. $10^{\mathrm{a}}$ ed. São Paulo (SP): HUCITEC; 2007.

11. Bardin L. Análise de conteúdo. Lisboa (PT): Edições 70; 1977.
12. Lucchese R, Barros S. A constituição de competências na formação e na prática do enfermeiro em saúde mental. Rev Esc Enferm USP. 2009 Mar; 43(1):152-60.

13. Jardim VMR, Cartana MHF, Kantorski LP, Quevedo ALA. Avaliação da política de saúde mental a partir dos projetos terapêuticos de centros de atenção psicossocial. Texto Contexto Enferm. 2009 Abr-Jun; 18(2):241-8.

14. Fontinele JK. Ética e bioética em enfermagem. $2^{\mathrm{a}}$ ed. Goiania (GO): AB; 2002.

15. Brêda MZB, Augusto LGSA. O cuidado ao portador de transtorno psíquico na atenção básica de saúde. Ciênc Saúde Colet [online]. 2001 [acesso 2008 Set 11]; 2(6):471-80. Disponível em: http:/ / www.scielo.br/ pdf/csc/v6n2/7017.pdf

16. Ministério da Saúde (BR). Secretaria de Atenção à Saúde. Departamento de Atenção Básica. Política Nacional de atenção básica. $4^{\text {a }}$ ed. Brasília (DF): MS; 2007.

17. Pessanha RV, Cunha FTS. A aprendizagem-trabalho e as tecnologias de saúde na Estratégia Saúde da Família. Texto Contexto Enferm. 2009 Abr-Jun; 18(2):233-40.

18. Cunha RR, Pereira LS, Gonçalves ASR, Santos EKA, Radünz V, Heidemann ITSB. Promoção da saúde no contexto paroara: possibilidade de cuidado de enfermagem. Texto Contexto Enferm. 2009 Jan-Mar; 18(1):170-6.

19. Figueiredo MD, Campos RO. Saúde mental na atenção básica à saúde de Campinas, SP: uma rede ou um emaranhado?. Ciênc Saúde Coletiva. 2009 Jan-Fev; 14(1):129-38.

20. Yasuí S. A produção do cuidado no território: "há tanta vida lá fora". In: Ministério da Saúde (BR). VI Conferência Nacional de Saúde Mental [online]. Brasília (DF): MS; 2010. Disponível em: http://portal.saude.gov.br/portal/arquivos/pdf/ cuidadosilvioyasui.pdf

24220020 - Icaraí, Niterói, RJ, Brasil

E-mail: virginia.damasio@gmail.com 